\title{
NÚCLEO DE EDUCAÇÃO AMBIENTAL DA UFSC: CONSTRUINDO SABERES ATRAVÉS DE EXPERIÊNCIAS COMPARTILHADAS
}

\author{
Isabela Tsutiya Andrade \\ Universidade Federal de Santa Catarina \\ isa.t.andrade@gmail.com \\ Juliana Machado Ferreira \\ Universidade Federal de Santa Catarina \\ jumachadoferreira@gmail.com \\ Thiago Teixeira Mendonça \\ Universidade Federal de Santa Catarina \\ thiagomendonca26@gmail.com
}

Audrey Luiza Almeida Gonçalves Universidade Federal de Santa Catarina audrey.sag@gmail.com

Marília Dietrich Schmitz Universidade Federal de Santa Catarina marilia.d.schmitz@gmail.com

Gustavo Kath Ackermann Universidade Federal de Santa Catarina ackergustavo@gmail.com

\begin{abstract}
Resumo
Essa publicação apresenta um breve relato sobre a história dos dez anos do Núcleo de Educação Ambiental (NEAmb) da Universidade Federal de Santa Catarina (UFSC) e enfatiza a importância da extensão universitária através de ações fundamentadas na Educação Ambiental realizadas por estudantes de graduação. É retratado o momento atual do Núcleo, valorizando os diversos projetos vigentes e compartilhando as experiências de como é fazer parte de um ambiente que incentiva a autonomia dos estudantes que, através de projetos de extensão, fomentam uma sociedade mais justa e uma cultura de sustentabilidade. O objetivo é apresentar as diversas esferas de atuação do NEAmb e seus métodos, a partir da apresentação dos projetos que estão em andamento e exposição da contribuição do Núcleo para a formação profissional e pessoal.

Palavras-chave: Educação Ambiental. Sustentabilidade. Extensão Universitária.

\section{ENVIRONMENTAL EDUCATION GROUP: CREATING KNOWLEDGE THROUGH SHARED EXPERIENCES}

Abstract

This publication presents a brief report on the history of the ten years of the Environmental Education Group (NEAmb) from Federal University of Santa Catarina (UFSC) and emphasizes the importance of university extension through actions based on Environmental Education carried out by undergraduate students. It presents the current moment of the Nucleus valuing the various projects in force and sharing the experiences of what it is like to be part of a place that encourages the autonomy of students who through extension projects foster a more just society and a culture of sustainability. The objective is to present the different spheres of NEAmb's actions and methods through the presentation of the projects that are in progress and show its contribution towards the student's personal and professional formation.

Keywords: Environmental Education. Sustainability. University Extension.

\section{NUCLEO DE EDUCACIÓN AMBIENTAL: CONSTRUYENDO SABERES ATRAVÉS DE EXPERIENCIAS COMPARTIDAS}

\section{Resumen}

Esta publicación presenta un breve relato sobre la historia de los diez años del Núcleo de Educación Ambiental (NEAmb) de la Universidad Federal de la Santa Catarina (UFSC) y enfatiza la importancia de la extensión universitaria a través de las acciones, fundamentadas en la Educación Ambiental, realizadas por estudiantes de grado. Se retrata el momento actual del Núcleo, valorizando los diversos proyectos vigentes y compartiendo experiencias sobre cómo es formar parte de un ambiente que incentiva la autonomía de los estudiantes que, a través de proyectos de extensión, fomentan una sociedad más justa y una cultura de sustentabilidad. El objetivo es presentar las diversas esferas de actuación del NEAmb y sus métodos, a partir de la presentación de los proyectos que están en marcha y la exposición de la contribución del Núcleo para la formación profesional y personal de los académicos.

Palavras clave: Educación Ambiental. Sustentabilidad. Extensión Universitaria. 
Núcleo de Educação Ambiental da UFSC: construindo saberes através de experiências compartilhadas

\section{INTRODUÇÃO}

A Pesquisa, o Ensino e a Extensão são elementos indissociáveis e igualmente essenciais dentro de uma Universidade. Juntos, proporcionam uma formação completa à comunidade universitária e é com o intuito de se trabalhar a visão integral de mundo, em detrimento da visão fragmentada, que a Universidade Federal de Santa Catarina (UFSC) se baseia nesses três pilares.

No que tange a Extensão Universitária, a promoção da educação continuada a partir da aplicação da teoria ao seu dia-a-dia promove essa integralização da universidade à comunidade externa. Segundo Rodrigues et al. (2013), essa parceria é potencializada e fortalecida quando acontece essa troca, pois traz benefícios para ambas as partes. Aquele que está na condição do aprender acaba aprendendo muito mais quando há o contato, uma vez que se torna muito mais gratificante praticar a teoria recebida dentro da sala de aula.

Dessa forma, por ser uma instituição federal, a UFSC tem a responsabilidade de por essa função social em prática, já que a instituição de ensino tem o dever de encorajar a comunidade universitária em conhecer a realidade local, com o propósito de ouvir e criar condições de melhoria de qualidade de vida, através dessas atividades extensionistas (JANTKE, 2013). Entretanto, o fato da extensão não ser curricularizada na maioria dos cursos agrava sua desvalorização e, consequentemente, uma menor disponibilidade de recursos revertidos para a mesma.

Como uma forma de fortalecer a extensão e repensar o ensino e a pesquisa frente às necessidades da sociedade, o Núcleo de Educação Ambiental da UFSC (NEAmb) atua junto à comunidade, valorizando a troca de conhecimento e experiências entre a população e a comunidade acadêmica.

Para isso, o Núcleo baseia-se nos projetos de extensão como ferramentas de transformação e na autogestão do grupo, com auxílio dos conselhos técnico, consultivo e gestor, além da realização de reuniões, oficinas e imersões.

O presente artigo tem o objetivo de apresentar as diversas esferas de atuação do NEAmb e seus métodos, a partir da apresentação dos projetos que estão em andamento e da exposição da contribuição do Núcleo para a formação profissional e pessoal dos acadêmicos.

Os projetos a serem apresentados no artigo são os que estão em vigência no ano de 2018, mostrando um breve histórico da criação destes e como contemplam seu público-alvo e o espaço ao qual estão inseridos. A apresentação das contribuições do Núcleo enquanto espaço de integração, por sua vez, traz as experiências dos relacionamentos vividos e como estas agregam aos participantes do NEAmb. 
Núcleo de Educação Ambiental da UFSC: construindo saberes através de experiências compartilhadas

\section{Núcleo de Educação Ambiental - NEAmb}

O Núcleo de Educação Ambiental da UFSC foi fundado em 2007 por alunos do curso de Engenharia Sanitária e Ambiental que buscavam experiências não oferecidas pelo currículo do curso. Somado a isso, os estudantes sentiam falta da prática de extensão e o contato com a comunidade ao redor da universidade.

O primeiro projeto contemplado ao NEAmb foi "Potencializando os Recursos Humanos e Naturais na Escola de Ensino Básico Getúlio Vargas", fundamentado na revitalização de um espaço ocioso da escola, que seria utilizado para vivências de Educação Ambiental (EA) com os alunos, através da construção coletiva de uma horta escolar e um sistema de captação da água da chuva.

Assim nasce o NEAmb, um movimento caracterizado pela construção coletiva e participativa, com sua dinâmica de trabalho baseada na transdisciplinaridade, no qual a cooperação e a coordenação entre as diversas disciplinas existem, mas sempre com o objetivo de transcendê-las.

Como ambiente plural, o Núcleo possui estudantes dos mais diversos cursos, culturas e idades. Atualmente, com sete projetos de extensão, o NEAmb conta com estudantes de Graduação em Engenharia Sanitária e Ambiental, Engenharia Civil, Ciências Econômicas, Agronomia, Design e Pós-Graduação em Oceanografia, trazendo a diversidade dos saberes para as relações de convívio e de desenvolvimento dos trabalhos.

Além dos projetos de extensão que ocorrem anualmente no núcleo, existem atividades já consolidadas que fazem parte da dinâmica do grupo e que têm grande importância para a aproximação e capacitação dos membros. Dentre estas atividades encontra-se o Mutirão EcoSolidário, realizado na sede rural do Instituto Çarakura e promovido pelos membros do NEAmb para os calouros da graduação em Engenharia Sanitária e Ambiental.

Em alternativa às atitudes desmoralizantes dos trotes tradicionais, os estudantes da primeira fase são convidados a passar um dia no instituto a fim de despertar a consciência socioambiental. Através de atividades fundamentadas no trabalho em equipe, os alunos experienciam a bioconstrução, o reconhecimento da Mata Atlântica e práticas alternativas de saneamento.

Outras atividades promovidas são as formações internas do núcleo, ou seja, encontros com o formato de apresentações e roda de conversa, nos quais são abordados elementos teóricos relacionados à Educação Ambiental. Além disso, estes encontros também são um ambiente de integração e conexão entre os membros, proporcionando uma grande troca de experiências. 
Núcleo de Educação Ambiental da UFSC: construindo saberes através de experiências compartilhadas

Os seminários anuais de Educação Ambiental, realizados pelo Núcleo, estimulam o contato dos estudantes da universidade com a comunidade externa e oportuniza um primeiro contato com a Educação Ambiental, apresentando um pouco dos projetos desenvolvidos no Núcleo e compartilhando as experiências obtidas.

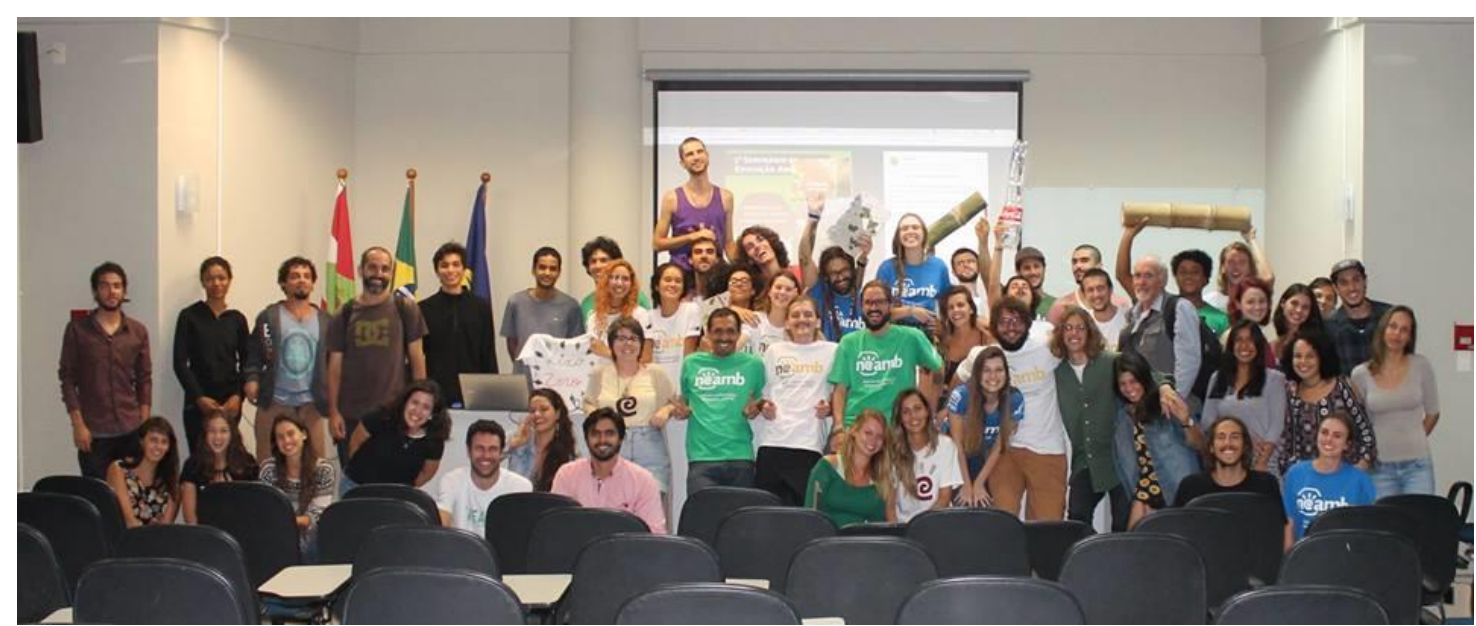

Figura 1 - V Seminário de Educação Ambiental - 10 anos do NEAmb

Fonte: Registrada pelos autores

\section{PROJETOS EM AÇÃO}

\section{Formação Continuada para Educadoras e Educadores Ambientais}

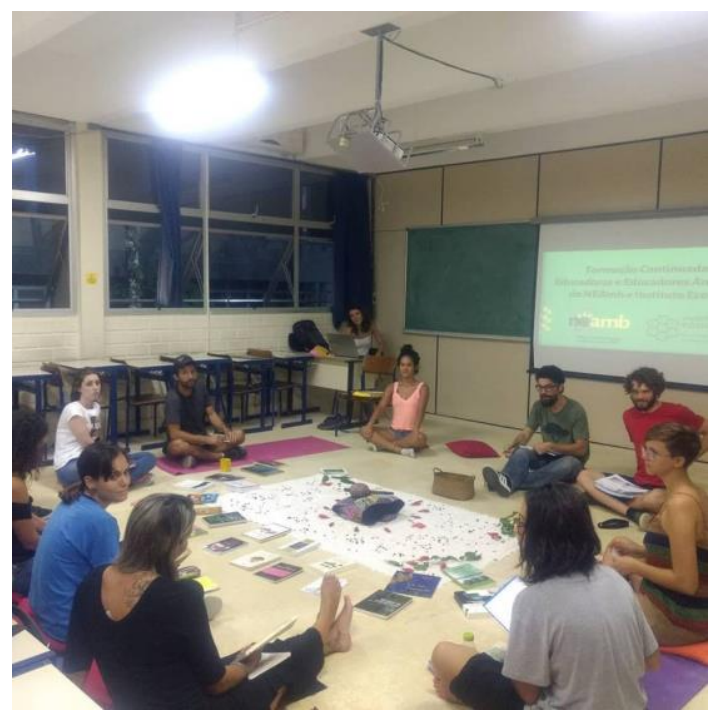

"Educar e educar-se, na prática da liberdade, é tarefa daqueles que pouco sabem - por isto sabem que sabem algo e podem assim chegar a saber mais - em diálogo com aqueles que, quase sempre, pensam que nada sabem, para que estes, transformando seu pensar que nada sabem em saber que pouco sabem, possam igualmente saber mais." (Paulo Freire)

Figura $2-1^{\circ}$ Encontro da Formação: Introdução - Eu e o Mundo Fonte: Registrada pelos autores 
Núcleo de Educação Ambiental da UFSC: construindo saberes através de experiências compartilhadas

Foi a partir da reflexão acerca da EA, que foca majoritariamente na consciência ecológica em detrimento da consciência ética e da justiça socioambiental, que se elaborou o Processo de Formação Continuada para Educadoras e Educadores Ambientais.

A proposta da Formação Continuada é de formar um coletivo de educadores aptos a atuarem com Educação Ambiental, reunindo diversos saberes do conhecimento humano e desenvolvendo uma consciência crítica e teórica, fundada em atividades práticas e cotidianas.

Ainda, a formação tem o intuito de evidenciar as relações entre os aspectos socioeconômicos com a degradação da natureza através de eixos temáticos comuns, como as práticas de agroecologia, gestão de resíduos, bioconstrução e plantas medicinais.

O projeto conta com uma turma composta por 20 pessoas, sendo estes, professores da rede pública, acadêmicos de diversos cursos da UFSC e representantes de comunidades de Florianópolis, com potencial de serem futuros multiplicadores da EA.

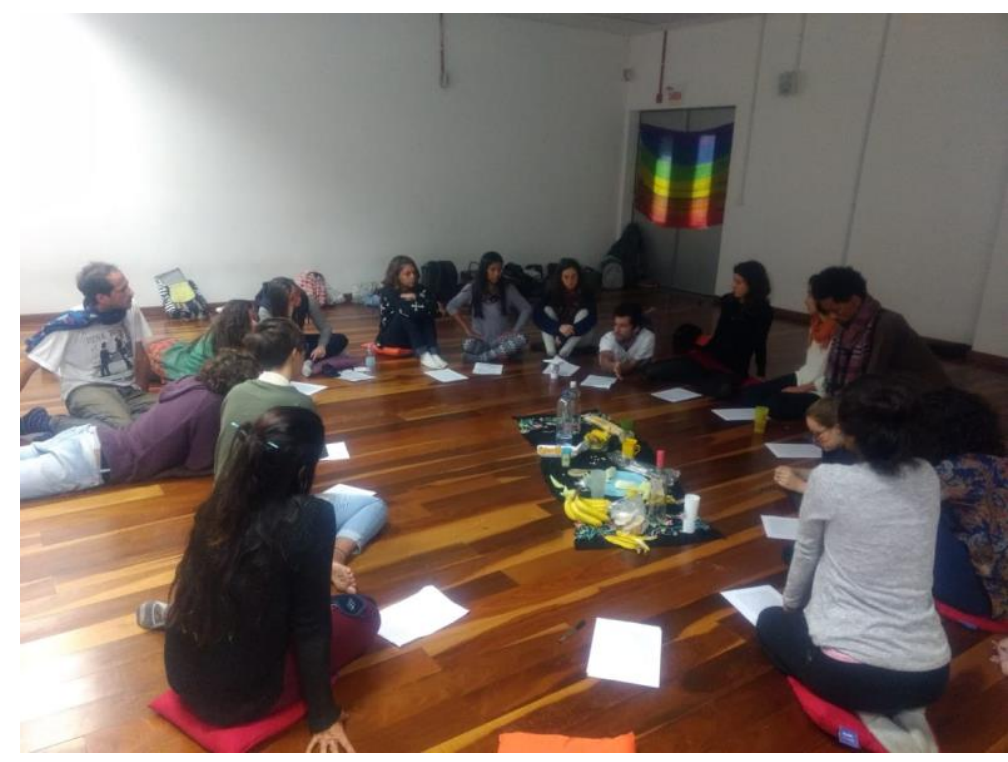

Figura 3 - $3^{\circ}$ Encontro da Formação: Sensorialidade, Sentidos e Emoções Fonte: Registrada pelos autores

Os temas abordados ao longo do ano são divididos em oito encontros, sendo eles:

1) Introdução: Eu com o mundo;

2) Transdisciplinaridade e Pensamento Complexo;

3) Sensorialidade, Sentidos e Emoções;

4) Teoria da Educação;

5) Relações Interpessoais, Governança e Bens Comuns;

6) Esferas Social e Política;

7) Ecologia e Meio Ambiente; 
Núcleo de Educação Ambiental da UFSC: construindo saberes através de experiências compartilhadas

8) Auto-conhecimento e Espiritualidade.

Os eixos temáticos foram pensados sob referenciais teóricos que dispunham sobre perspectivas e diretrizes de construção de uma EA sustentável, abordando práticas educativas amplas e de potencial transformador. Cada tema trabalha uma área específica, mas ao analisar o todo, a conexão entre os eixos se mostra necessária para a compreensão da totalidade trabalhada na EA.

\section{Mãos à Horta}

O projeto Mãos à Horta surgiu a partir de um desejo dos membros do NEAmb de transformar espaços ociosos do campus da UFSC em espaços educadores, buscando promover e resgatar os saberes dos usos de plantas medicinais e plantas alimentícias não convencionais (PANC's).

A transformação destes espaços ociosos causou uma mudança na paisagem monótona do Centro Tecnológico da UFSC. As hortas não atraem somente os olhares dos polinizadores, mas também das pessoas que costumam frequentar ou transitar por esse ambiente.

Após 3 anos de atuação, o projeto conquistou mais espaços dentro do Centro Tecnológico e foi, aos poucos, transformando-os e trazendo-lhes novas perspectivas. As hortas criadas são mantidas pelo projeto, principalmente através de atividades coletivas de manejo agroecológico, pautado na busca do aumento da fertilidade dos solos, a biodiversidade e a nãoutilização de substâncias químicas ou tóxicas.

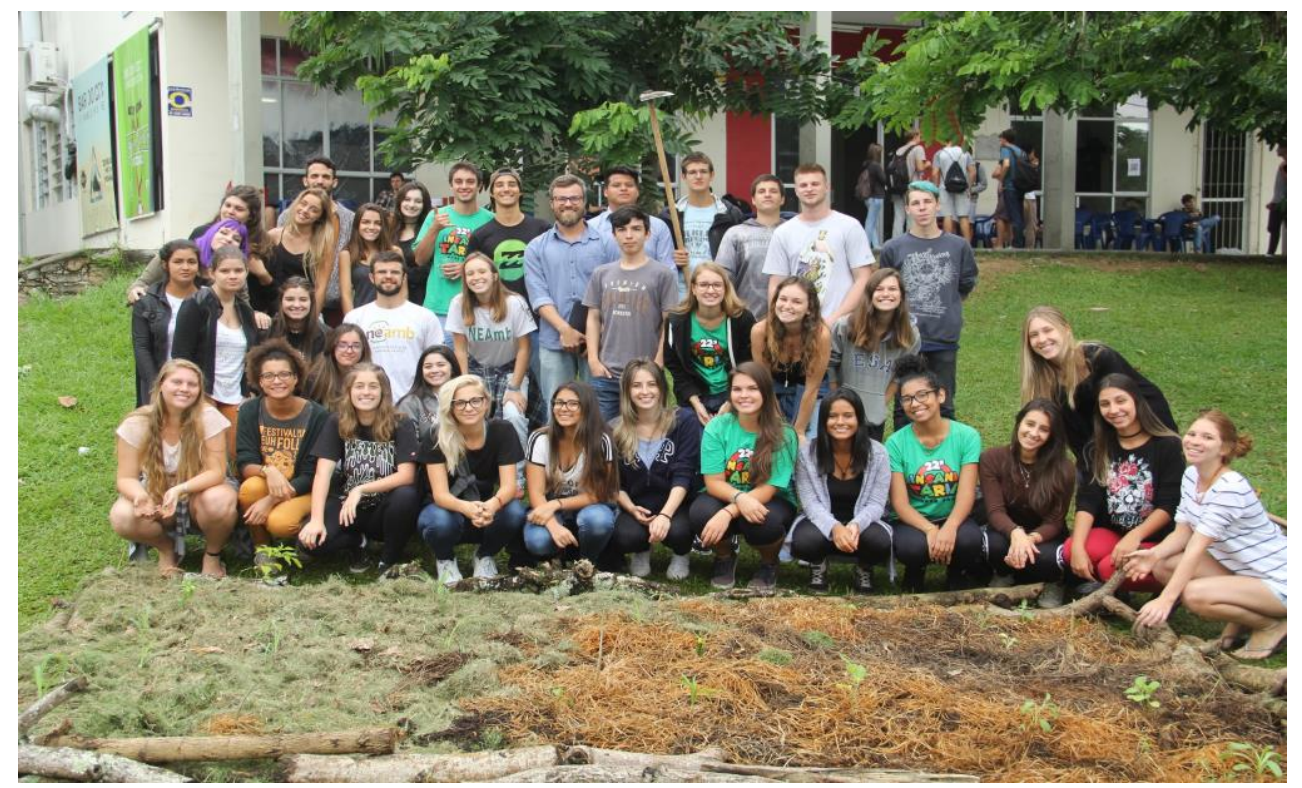

Figura 4: Canteiro realizado com calouros da Engenharia Sanitária e Ambiental 
Núcleo de Educação Ambiental da UFSC: construindo saberes através de experiências compartilhadas

Fonte: Registrado pelos autores

O projeto realiza oficinas, gratuitas e abertas à comunidade sobre técnicas de manejo do solo e das plantas, a fim de disseminar e resgatar conhecimentos populares a partir da visão holística da agroecologia. Sendo as oficinas espaços importantes que permitem o contato entre a comunidade acadêmica e a comunidade externa, fortalecendo laços com outros grupos ambientais e de educação da Universidade, proporcionando a autonomia, o empoderamento dos participantes e a descentralização da produção de alimentos.

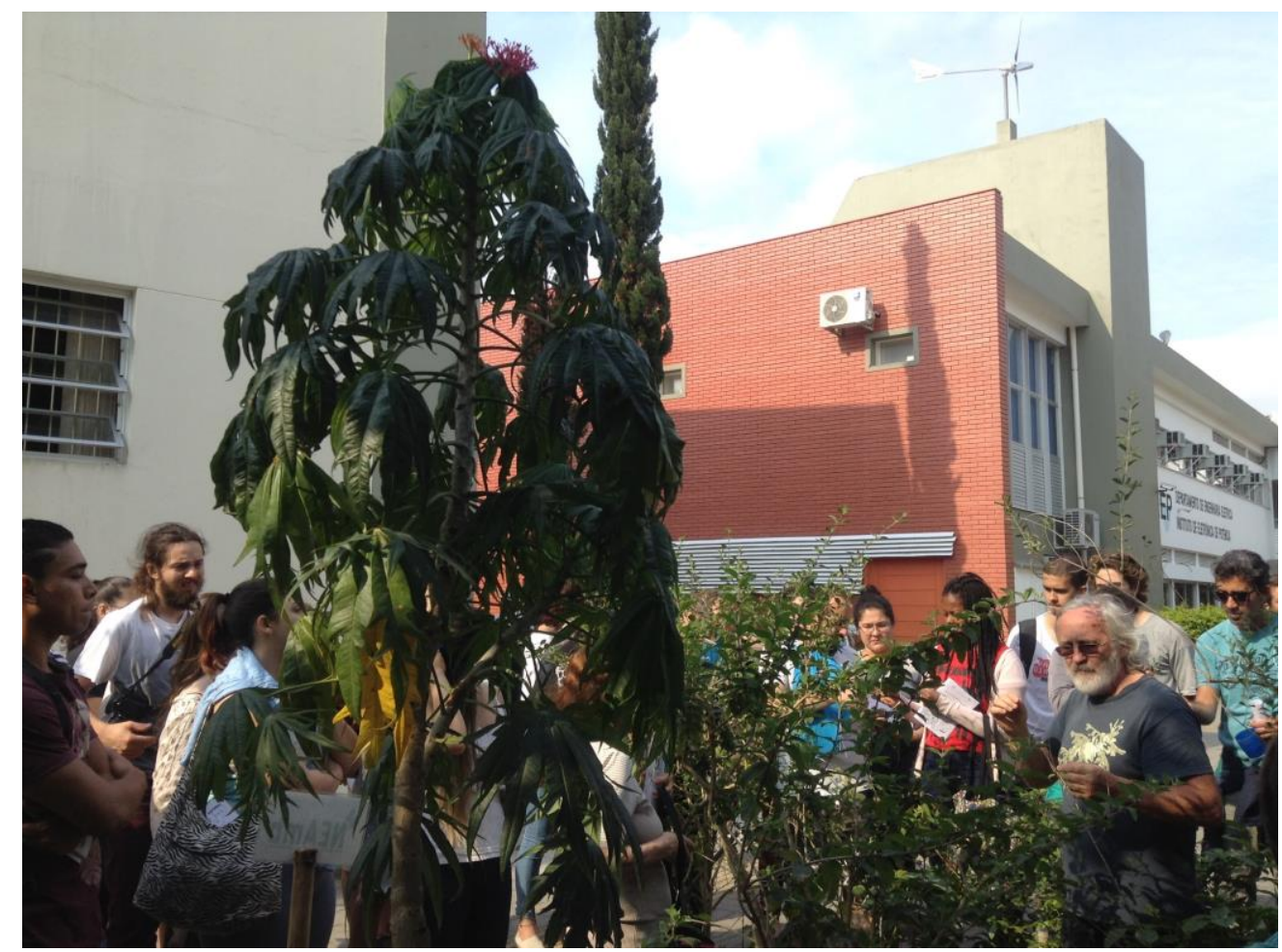

Figura 5: Oficina de Plantas Medicinais Fonte: Registrado pelos autores

Espera-se, portanto, que a troca de saberes e experiências proporcionadas pelas atividades do projeto promova uma maior autonomia à comunidade da UFSC e transformem estes espaços em ambientes de bem-estar em prol da EA para todos.

\section{Lixo Zero}

Iniciada em 2015, como um projeto no Colégio de Aplicação (C.A.) da UFSC, a metodologia Desafio Lixo Zero foi replicada, em 2016, para mais duas escolas: Escola Básica Municipal (EBM) Donícia Maria da Costa e Escola Básica Vitor Miguel. 
Núcleo de Educação Ambiental da UFSC: construindo saberes através de experiências compartilhadas

A EA, inserida no cotidiano escolar, foi trabalhada a partir do conceito Lixo Zero, a fim de que, no final do ano, a Semana Lixo Zero fosse realizada, tendo como objetivo a redução da produção e do consumo de resíduos. Foi um sucesso, no Colégio de Aplicação da UFSC a redução foi de 50\% e, na E.B.M, foi de 33\%.

Em 2016, um novo projeto, "Promovendo a economia circular e solidária a partir do conceito Lixo Zero", foi escrito para que se continuasse o trabalho. O foco, porém, era voltado para a E.B.M Donícia Maria da Costa, atuando na promoção da Economia Circular e Solidária (geração de renda a partir de atividades ambientalmente positivas).

Ao longo do ano, diversas atividades foram realizadas com um coletivo de alunos. Dentre estas, oficinas de minhocário, papel reciclado, eco-cadernos e brincos reciclados, todos relacionados à reciclagem e reutilização, nas quais foram vendidos, ao final do ano, os itens produzidos nelas, gerando grande reconhecimento do projeto na escola.

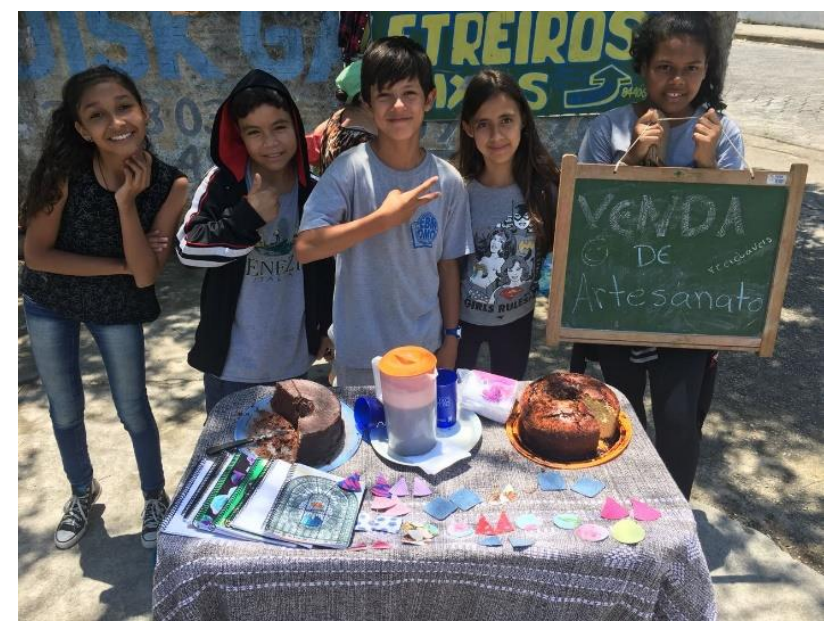

Figura 6: Alunos do Coletivo Lixo Zero Fonte: Registrado pelos autores

Em 2017, o projeto foi reescrito como uma continuação do anterior. A ideia para o ano seguinte era de continuar com as práticas realizadas anteriormente, trabalhando, também, na instituição da Educação Ambiental no Plano Político Pedagógico (PPP) do colégio.

O PPP deve ser discutido juntamente com os professores, através de encontros de formação com base na Pedagogia do Amor (SILVA, 1998), em que experiências pessoais são valorizadas para que, conjuntamente, uma proposta final seja encontrada. Paralelamente, um dos integrantes voluntários está escrevendo o plano de gerenciamento de resíduos sólidos (PGRS) da Escola para seu Trabalho de Conclusão de Curso, dispondo do apoio de todo o grupo. 
Núcleo de Educação Ambiental da UFSC: construindo saberes através de experiências compartilhadas

\section{BioAção - Bioconstrução no Aplicação}

A construção com elementos naturais, intitulada Bioconstrução, se mostra com grande potencial transformador não só de espaços, mas também de pessoas. A utilização de recursos naturais, que fazem parte do nosso cotidiano, e o fato de suas técnicas serem muitas vezes simples e intuitivas, faz da bioconstrução uma bela ferramenta para aliar a teoria e a prática dentro do ambiente escolar, ao passo que possibilita também à escola, por si própria, agir em suas demandas e sonhos através dos recursos locais.

O Colégio de Aplicação conta com um grande terreno de área verde que possui inúmeros bambuzais "esquecidos" e que poderiam ter os mais variados usos. Percebendo tal potencialidade e a partir das experiências nos anos de 2015 e 2016 com o Coletivo Lixo Zero, desde 2017 este projeto busca atuar nessas demandas e sonhos através do uso do bambu e da terra local.

Em 2017, no seu primeiro ano, o projeto focou suas atenções nos contraturnos do Ensino Médio, atuando como atividade extracurricular com alunos interessados. Foram realizadas com eles oficinas de colheita e tratamento de bambu, culminando na concepção e construção conjunta de uma Lixeira Ecológica de Bambu, a ser utilizada nas Festa das Famílias da escola como contentor de recicláveis.

Em 2018, o projeto dividiu-se em duas frentes. A primeira sendo a continuação da atuação nas demandas escolares, que neste ano se focam nas construções de um bicicletário de bambu, de uma estrutura coberta para os lixos semanais chamada de Residuário, e de um espaço de convivência feito em bambu e terra nomeado Praça Bambu. A outra frente atua diretamente dentro da sala de aula, explorando a Bioconstrução como ferramenta pedagógica que contextualiza conteúdos curriculares, através da execução de um Plano de Aulas em conjunto com os professores dos $6^{\circ}$ anos de Ciências, de Geografia e de Matemática. 


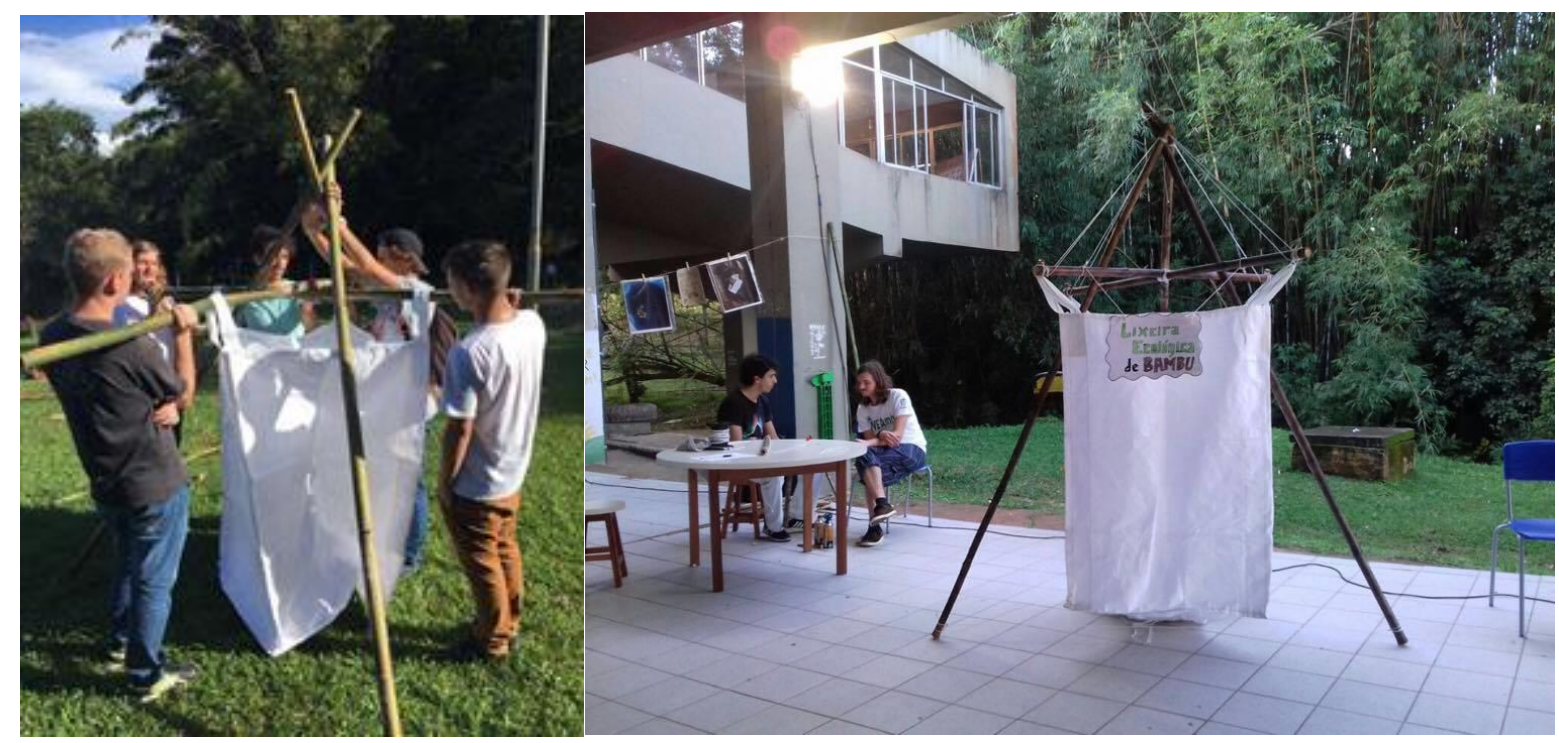

Figuras 7 e 8: Construção de lixeiras de bambu para ecobags

Fonte: Registrado pelos autores

\section{Associação de Catadores: Recicla Floripa}

Com apoio da Secretaria de Estado de Assistência Social, Trabalho e Habitação de Florianópolis, o projeto foi iniciado no ano de 2015 na Associação Recicla Floripa. O objetivo era valorizar as Associações de Catadores de Materiais Recicláveis do município.

Com o sucesso das primeiras ações realizadas e baseado em metodologias empregadas em outras instituições, o projeto se ampliou e chegou à Escola Desdobrada Municipal José Jacinto Cardoso no ano de 2017, onde atuou com crianças a importância dos catadores dentro da cadeia do gerenciamento de resíduos sólidos urbanos, promovendo a visibilidade da profissão.

Pautadas nas práticas de EA e Governança, o projeto permanece acontecendo na Associação Recicla Floripa e agora encontra-se em processo de finalização do licenciamento do local, que foi trabalhado durante os anos de atuação. 
Núcleo de Educação Ambiental da UFSC: construindo saberes através de experiências compartilhadas

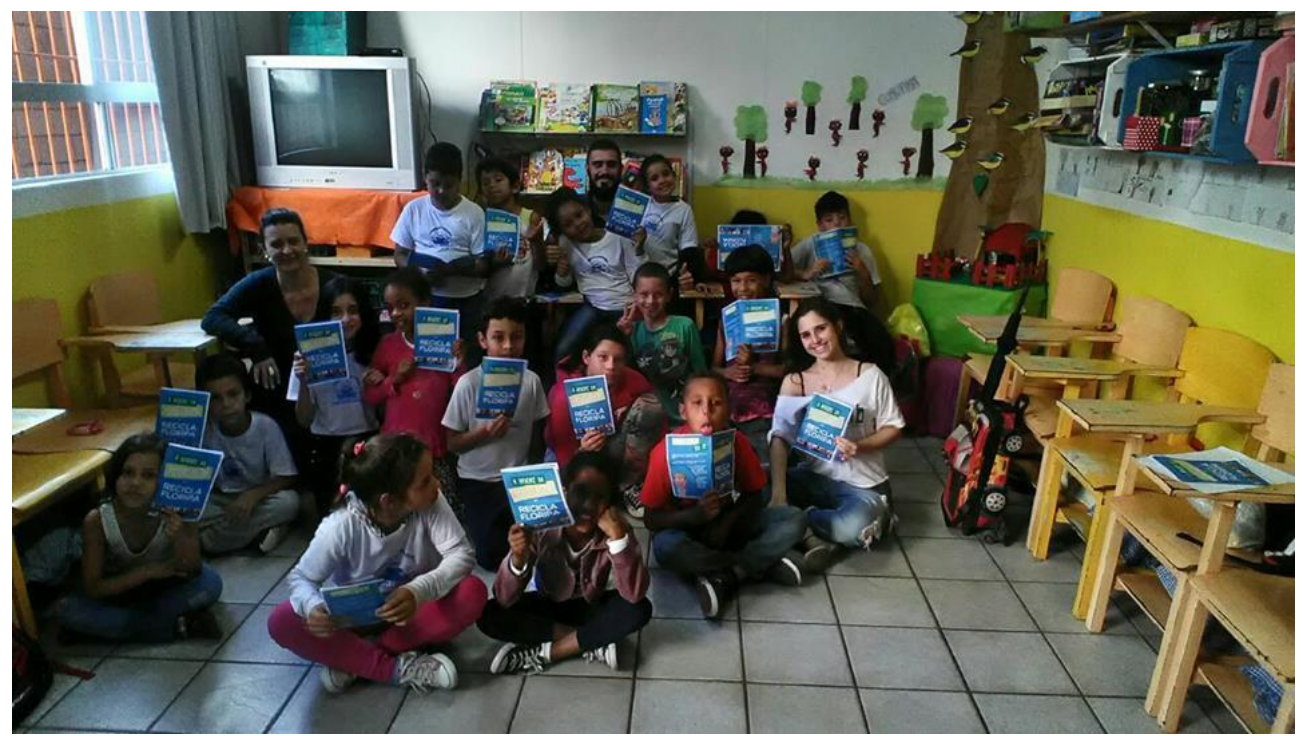

Figura 9 - Atividade com as crianças e membros da Associação de Catadores

Fonte: Registrada pelos autores

Para 2018, espera-se construir junto à comunidade e à Associação uma "Brechóteca", que se constitui, basicamente, de um brechó e uma biblioteca abastecidos por doações e seleções de objetos triados, capazes de serem reempregados.

\section{Captando Consciência: Valorização da Água da Chuva e dos Saberes}

Iniciado em 2018, o projeto foi concebido devido a uma demanda provinda da própria comunidade do Colégio de Aplicação da UFSC. Atualmente, é conduzido por 5 membros estudantes da UFSC e coordenado por uma professora da Engenharia Sanitária e Ambiental, especializada em hidrologia e hidráulica.

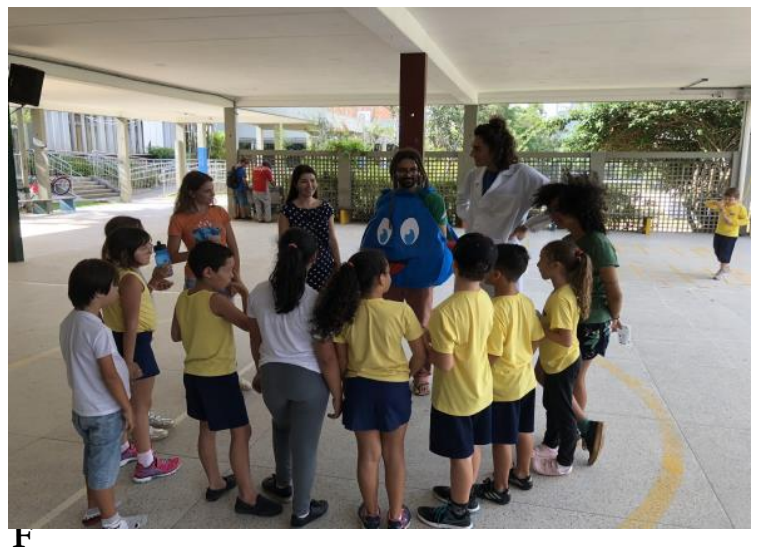

Figura 10: Intervenção de Gute, personagem em forma de gota, no Dia Mundial da Água.

Fonte: Registrado pelos autores

As atividades no primeiro semestre do projeto preveem três frentes principais: orçamento, análise e posterior dimensionamento de um sistema de captação de água da chuva. Atrelado à construção dos saberes, o projeto se utiliza dos conceitos de educação ambiental. 
Núcleo de Educação Ambiental da UFSC: construindo saberes através de experiências compartilhadas

A partir do segundo semestre, pretende-se realizar a operação e implementação do sistema de captação das águas pluviais em conjunto com a comunidade do colégio, aplicando também intervenções artísticas como forma pedagógica de aprendizado das crianças. Gute, personagem em forma de gota, atuará no colégio de forma elucidativa para compor com a equipe de projeto a formação interdisciplinar dos alunos, valorizando os saberes e a água, elemento essencial para a vida na Terra.

\section{A CONVIVÊNCIA NO UNIVERSO NEAMB}

Além de fortalecer o aprendizado e o crescimento pessoal dos membros nas mais diversas áreas do conhecimento enquanto agentes de mudança socioambiental, o NEAmb também proporciona à comunidade um ganho de experiências.

Participar do Núcleo permite, além de incentivar os alunos a conhecer a Extensão, o desenvolvimento de habilidades, autoconhecimento, empoderamento, autonomia individual de seus membros e a descoberta de gostos pessoais.

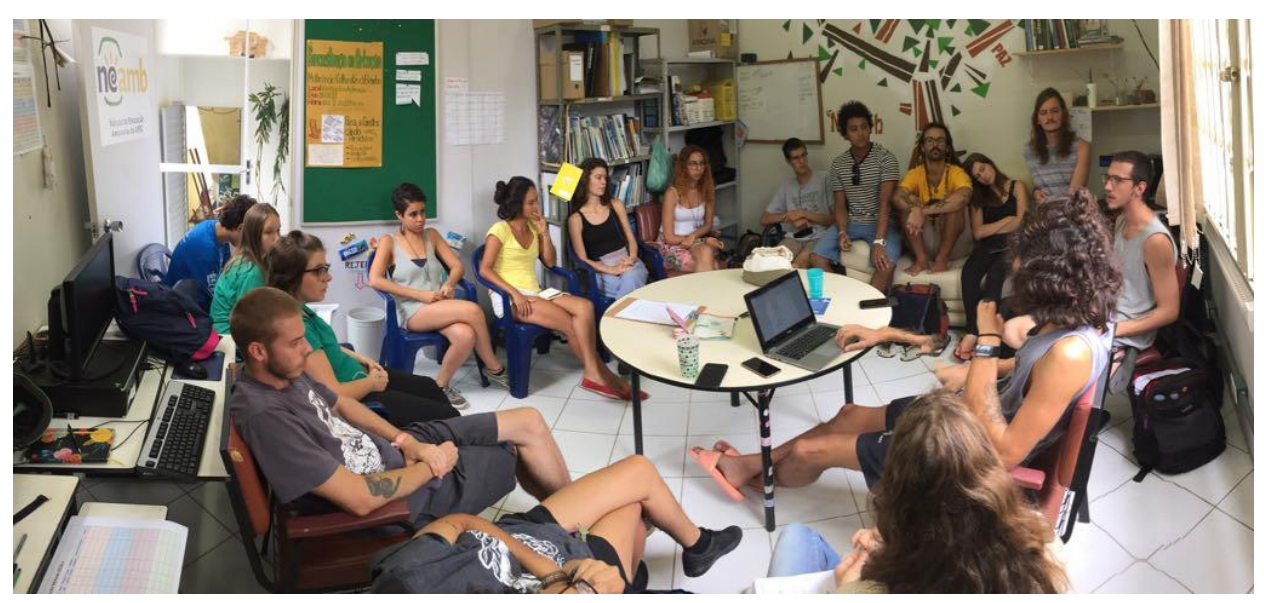

Figura 11: Reunião semanal dos membros do Núcleo

Fonte: Registrada pelos autores

Quando introduzidos às atividades dos projetos, os membros experimentam a vivência extracurricular, através da promoção do diálogo com a comunidade externa e interna da UFSC, público alvo dos projetos do NEAmb. Somado a isso, conseguem praticar o aprendizado obtido em sala de aula, oferecido pelo Ensino e Pesquisa.

Fora do ambiente de trabalho dos projetos, o Núcleo conta com uma sala, na qual os membros se encontram e compartilham momentos de distração, entretenimento e diversão dentro do âmbito universitário. Além disso, as formações internas agregam aos membros, de 
Núcleo de Educação Ambiental da UFSC: construindo saberes através de experiências compartilhadas

forma a se tornarem educadores ambientais alinhados com uma consciência pautada na ética e na justiça socioambiental.

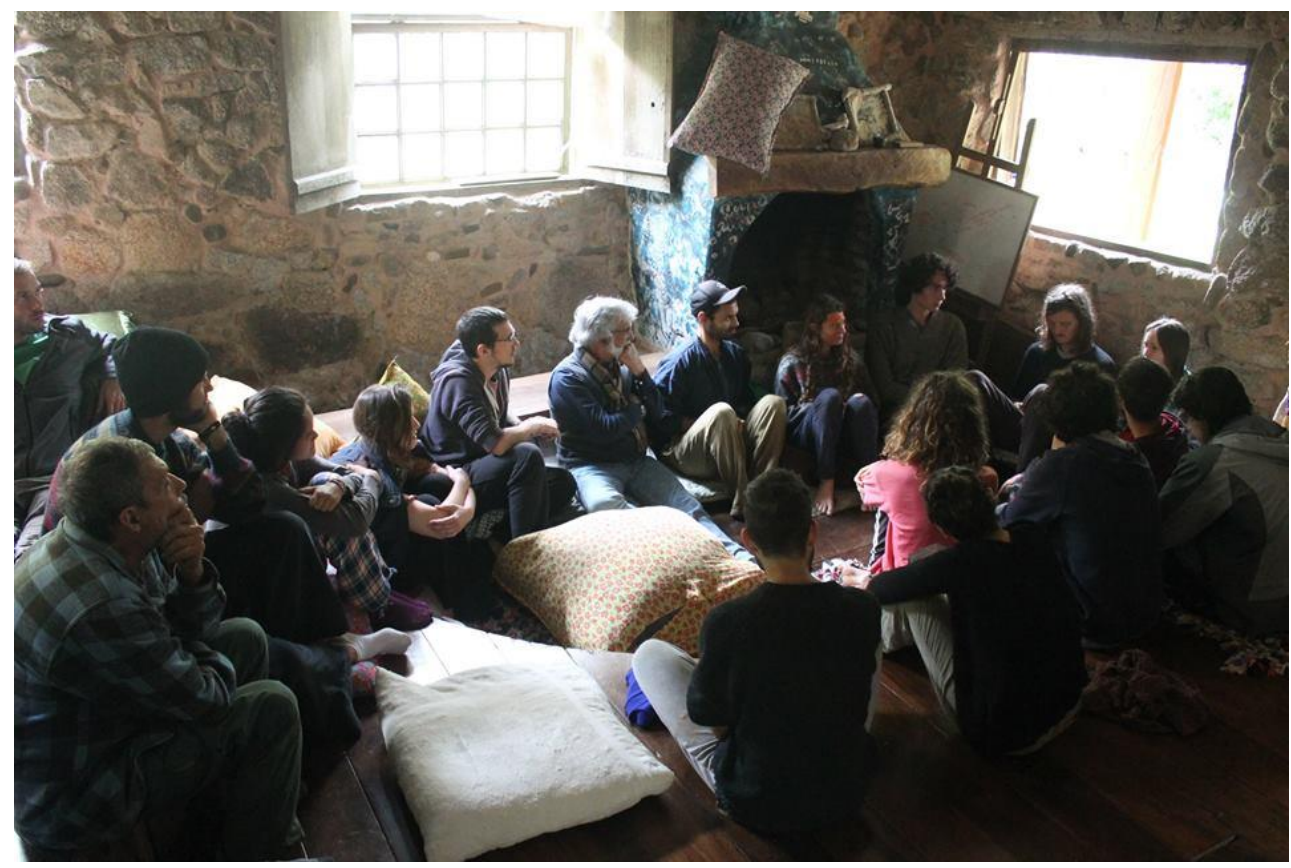

Figura 12: Formação Interna do NEAmb, realizada na sede rural do Instituto Çarakura Fonte: Registrado pelos autores

A forma autogestionada em que se encontra o Núcleo promove o desenvolvimento do espírito de liderança e consolidação de um dos valores do NEAmb, o chamado "cheguedalismo", termo que representa a capacidade do estudante de se tornar autônomo em suas atividades, sentindo-se seguro e empoderado para desempenhá-las. A horizontalidade organizacional do Núcleo permite que as decisões sejam tomadas de forma coletiva, desenvolvendo o espírito comunitário nos membros.

\section{CONSIDERAÇÕES FINAIS}

O progresso dos projetos do Núcleo demonstra os resultados que surgem da oportunidade dada pela Universidade através da Extensão Universitária. Estabelecer contato com a comunidade externa e poder devolver a ela o investimento dado é, além de aprender, romper o conceito de bolha acadêmica. Dessa forma, o NEAmb, enquanto agente atuante na sociedade, cumpre com o dever de dar continuidade ao processo de desenvolvimento de atividades desse mérito, trazendo consigo novos agentes do saber.

Ademais, para quem faz parte do Núcleo, estar presente nele e nos projetos significa conhecer pessoas, abrir a mente para novas possibilidades, realidades e novas formas de pensar, 
Núcleo de Educação Ambiental da UFSC: construindo saberes através de experiências compartilhadas

além de simbolizar o acolhimento e o refúgio para os estudantes que estão em busca de ampliar seus horizontes.

\section{REFERÊNCIAS}

JANTKE, Regina Vazquez Del Rio; CARO, Sueli Maria Pessagno. A extensão e o exercício da cidadania. In: SÍVERES, Luiz (Org.). A extensão universitária como princípio de aprendizagem. 1. ed. Brasília: Liber Livro Editora, 2013. cap. 3, p. 97-108. v. 1. Disponível em: $<$ http://unesdoc.unesco.org/images/0023/002320/232083por.pdf>. Acesso em: 05 jul. 2018.

MOURE, Eduardo Schnitzler. et al. Núcleo de Educação Ambiental do CTC: Uma experiência de estudantes comprometidos com a extensão universitária pela sustentabilidade. Revista Extensio, Florianópolis, v. 12, n. 19, p. 109-124, jun. 2015.

RODRIGUES, Andréia Lilian et al. Contribuições da Extensão Universitária na Sociedade.

Cadernos de Graduação - Ciências Humanas e Sociais, Aracaju, v. 1, n. 16, p. 141-148, mar. 2013. Disponível em:

$<$ https://periodicos.set.edu.br/index.php/cadernohumanas/article/viewFile/494/254>. Acesso em: 13 maio 2018.

SILVA, Daniel José da. O PARADIGMA TRANSDISCIPLINAR: Uma perspectiva metodológica para a pesquisa ambiental. 1999. 29 p. Workshop (WORKSHOP SOBRE INTERDISCIPLINARIDADE) - Instituto Nacional de Pesquisas Espaciais, Florianópolis, 1999. 1.

SILVA, Daniel José da . Uma abordagem cognitiva ao planejamento Estratégico do Desenvolvimento Sustentável. Florianópolis: Tese de Doutorado (Programa de Pós-Graduação em Engenharia de Produção) da Universidade Federal de Santa Catarina, 1998

Recebido em: 25/05/2018

Aceito em: 30/07/2018 